\title{
The nuclear hormone receptor Coup-TFII is required for the initiation and early maintenance of Prox1 expression in lymphatic endothelial cells
}

\author{
R. Sathish Srinivasan, ${ }_{1}^{1}$ Xin Geng, ${ }^{1}$ Ying Yang, ${ }^{1}$ Yingdi Wang, ${ }^{1}$ Suraj Mukatira, ${ }^{2}$ Michèle Studer, ${ }^{3}$ \\ Marianna P.R. Porto, ${ }^{1}$ Oleg Lagutin, ${ }^{1}$ and Guillermo Oliver ${ }^{1,4}$ \\ ${ }^{1}$ Department of Genetics and Tumor Cell Biology, St. Jude Children's Research Hospital, Memphis, Tennessee 38105, USA; \\ ${ }^{2}$ Hartwell Center for Bioinformatics and Biotechnology, St. Jude Children's Research Hospital, Memphis, Tennessee 38105, USA; \\ ${ }^{3}$ Developmental Disorders Program, Telethon Institute of Genetics and Medicine, 80131 Napoli, Italy
}

\begin{abstract}
The homeobox gene Prox1 is crucial for mammalian lymphatic vascular development. In the absence of Prox1, lymphatic endothelial cells (LECs) are not specified. The maintenance of LEC identity also requires the constant expression of Prox1. However, the mechanisms controlling the expression of this gene in LECs remain poorly understood. The SRY-related gene Sox18 is required to induce Prox1 expression in venous LEC progenitors. Although Sox18 is also expressed in embryonic arteries, these vessels do not express Prox1, nor do they give rise to LECs. This finding suggests that some venous endothelial cell-specific factor is required for the activation of Prox1. Here we demonstrate that the nuclear hormone receptor Coup-TFII is necessary for the activation of Prox1 in embryonic veins by directly binding a conserved DNA domain in the regulatory region of Prox1. In addition, we show that the direct interaction between nuclear hormone receptors and Prox1 is also necessary for the maintenance of Prox1 expression during early stages of LEC specification and differentiation.
\end{abstract}

[Keywords: Lymphatics; Prox1; Coup-TFII; mouse; endothelial cell]

Supplemental material is available at http://www.genesdev.org.

Received August 31, 2009; revised version accepted February 18, 2010.

Because of differences in oncotic pressure, water, plasma, and other molecules continually escape from blood vessels. White blood cells also actively exit the blood vessels to take part in immune surveillance. One of the main functions of the lymphatic vasculature is to return these extravasated cells and molecules to the blood circulation.

Work performed during the last decade identified a number of key players required for the development of the mammalian lymphatic vasculature (Oliver and Alitalo 2005; Oliver and Srinivasan 2008), and determined that lymphatic endothelial cells (LECs) originate from embryonic veins (Srinivasan et al. 2007). One key player in the process of lymphatic vasculature formation is the homeobox gene Prox1. In mice, starting at around embryonic day 9.75 (E9.75), the expression of Prox 1 is detected in a subpopulation of endothelial cells (ECs) in the embryonic veins that will eventually acquire an LEC

${ }^{4}$ Corresponding author.

E-MAIL guillermo.oliver@stjude.org; FAX (901) 595-6035.

Article is online at http://www.genesdev.org/cgi/doi/10.1101/gad.1859310. phenotype (Wigle and Oliver 1999; Wigle et al. 2002; Srinivasan et al. 2007). As development progresses, the specified LECs migrate from the veins and form the primitive lymph sacs from which the entire lymphatic vasculature is eventually derived. In Prox1-null embryos, LEC specification does not take place; therefore, mutant embryos are devoid of a lymphatic vasculature (Wigle and Oliver 1999). Furthermore, conditional inactivation of Prox1 during embryonic or postnatal stages is sufficient to dedifferentiate LECs back into blood ECs (Johnson et al. 2008).

Recent work identified the SRY-related HMG domain transcription factor Sox18 as an upstream regulator of Prox1 expression in venous LEC progenitors (Francois et al. 2008). In Sox18-null embryos, Prox1 expression is not induced in venous ECs; therefore, LEC specification does not occur, and the formation of the lymphatic vasculature is arrested (Francois et al. 2008). Sox18 expression is maintained in differentiating LECs and in forming lymphatic vessels up to around E14.5 (Francois et al. 2008). Interestingly, Sox18 is expressed endogenously not only in venous ECs that subsequently differentiate into LECs, but also in arterial ECs (Pennisi et al. 
2000); however, in the latter cells, Sox18 expression is not sufficient to promote Proxl expression, and therefore LEC specification. This argues that, in veins, some other as-yet-unknown factor cooperates with Sox18 during the induction of Prox1, and a likely candidate for this role is the orphan nuclear receptor Coup-TFII.

Because the mammalian lymphatic vasculature is venous-derived, the presence of embryonic veins is a prerequisite for lymphatic vasculature formation. The expression of Coup-TFII is required to promote and maintain venous identity (You et al. 2005), and very few (if any) LECs are present in Tie2-Cre;Coup-TFIf ${ }^{f / f}$ conditional mutant mouse embryos in which venous fate is lost (Srinivasan et al. 2007). In addition, results from studies of ECs maintained in culture suggest that Coup-TFII activity also helps maintain the LEC phenotype, a role that could be mediated by its protein-protein interaction with Prox1 (Lee et al. 2009; Yamazaki et al. 2009).

In this study, and by using a variety of animal models, we identify Coup-TFII as a direct in vivo activator of Prox1 expression in venous LEC progenitors. We determined that this activation is mediated by the direct binding of Coup-TFII to a conserved site in the regulatory region of Prox1 that is required for the initial LEC specification step. Subsequently, interaction of Prox1 with nuclear hormone receptors (most likely Coup-TFII) is necessary for maintaining Prox1 expression.

\section{Results}

Generation and characterization of the Prox $1^{+/ G F P C r e}$ line

To better dissect the early steps in the specification of the LEC phenotype and increase our understanding of Prox1 regulation and function in this process, we took advantage of a novel Proxi ${ }^{+/ G F P C r e}$ mouse strain that we generated by inserting a GFPCre expression cassette into the Prox1 genomic locus (Supplemental Fig. 1). In this strain, Cre recombinase was constitutively expressed by all LECs at all time points, and GFP can be used as a reporter of Prox1 promoter activity. Similar to the previously reported $\operatorname{Prox} 1^{+/ L a c Z}$ mice (Wigle and Oliver 1999), the generated Prox $1^{+/ G F P C r e}$ animals were also haploinsufficient, with a reduced rate of postnatal survival in the NMRI background and almost $100 \%$ lethality in all other tested backgrounds.

To better characterize this novel mouse strain, we first performed lineage-tracing analysis by crossing the Prox $1^{+/ G F P C r e}$ strain with the $R 26 R$ reporter line (Soriano 1999). As shown in Supplemental Figure 2, A and B, we observed similar X-gal staining patterns in E11.5 Prox $1^{+/ G F P C r e} ;$ R26R embryos and Prox $1^{+/ L a c Z}$ embryos, a result indicating that Prox $1^{+/ G F P C r e}$ faithfully recapitulates Prox1 expression. At this stage, Prox $1^{+} \beta$-gal ${ }^{+}$LECs were detected around the anterior cardinal vein in a polarized manner (Supplemental Fig. 2C, arrows). Later, at approximately E15.5, all of the GFP ${ }^{+}$LECs lining the lymph sacs were also $\beta-\mathrm{gal}^{+}$(Supplemental Fig. 2D, arrows). At postnatal day $1(\mathrm{P} 1)$, we observed Prox $1^{+} \beta$-gal ${ }^{+}$Lyve $^{+}$LECs in the paratracheal lymph plexus (PTLP) (Supplemental Fig. 2E-H) and in the mesentery (Supplemental Fig. 2I-L).

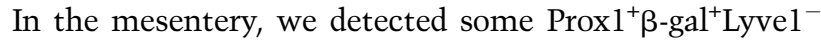
LECs that most likely correspond to those in the collecting lymphatic vessels (Supplemental Fig. 2L, arrows).

$\mathrm{X}$-gal staining of embryos resulting from crossing Prox ${ }^{+/ G F P C r e} ;$ R26R mice with wild-type mice showed that all embryos inheriting the $R 26 R$ allele expressed $\beta$-gal in all somatic cells. This result indicated that Cre activity is present in the germ cells of Prox $1^{+/ G F P C r e}$ mice (data not shown). Therefore, when using Prox $1^{+/ G F P C r e}$ mice, we must be mindful that one of the floxed alleles will be deleted in the germline $(\Delta)$, and the other will be deleted in a tissue-specific manner.

\section{Prox1 expression in LECs has two distinct phases}

Our previous detailed characterization of Prox1-null embryos showed that, contrary to the Prox 1 heterozygous embryos, in these mutant embryos, $\beta$-gal-expressing (Prox1 locus-tagged) ECs are detected for only a few days (E9.75-E11.5) (Wigle and Oliver 1999; Wigle et al. 2002). To identify the cause of this loss of Prox1 expression and the ultimate fate of those ECs, we generated Prox $1^{+/ G F P C r e}$ and Prox1 $1^{\text {LacZ/GFPCre }}$ (Prox1-null) embryos and compared the numbers of $\mathrm{GFP}^{+} \mathrm{PECAM}^{+}$cells present in serial sections made along the anterior cardinal vein at E10.5 and E11.5. We found no obvious differences between those embryos at E10.5 (Supplemental Fig. 3A). However, at E11.5, the number of GFP'PECAM ${ }^{+}$cells had nearly doubled in the Prox $1^{+/ G F P C r e}$ embryos and was moderately reduced in the Prox $1^{\text {LacZ/GFPCre }}$ embryos (Supplemental Fig. 3A). We reasoned that this reduction in cell number could have been caused by reduced cell proliferation, increased cell death, or an arrest in Prox1 and, therefore, GFP expression. Only a small percentage of $\mathrm{GFP}^{+}$ECs were also positive for PH3 (Supplemental Fig. 3B), a marker of proliferating cells, in E10.5 and E11.5 Prox $1^{+/ G F P C r e}$ and Prox $1^{\text {LacZ/GFPCre embryos. This }}$ result supports our previous proposal (Wigle et al. 2002; Srinivasan et al. 2007) that the veins continually generate LECs, and that reduced cell proliferation is not responsible for the observed reduction in cell number in Prox $1^{\text {LacZ/GFPCre }}$ embryos. Similarly, we found no obvious differences in the numbers of $\mathrm{TUNEL}^{+} \mathrm{GFP}^{+}$cells in Prox $1^{+/ G F P C r e}$ and Prox $1^{\text {LacZ/GFPCre }}$ embryos at either time point (Supplemental Fig. 3C-F).

To determine whether Prox1 expression is arrested in Prox1-null cells, we prepared similar sections of E10.5 and E11.5 Prox $1^{+/ G F P C r e}$ and Prox ${ }^{\text {LacZ/GFPCre embryos and }}$ immunostained them with antibodies against GFP and PECAM, and then analyzed the sections by using confocal imaging. The initial migration of LECs from the veins is independent of Proxl, as $\mathrm{GFP}^{+}$cells could be seen migrat-

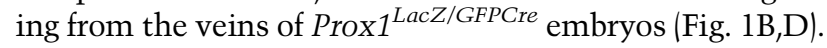
At E10.5, the intensity of GFP staining in the ECs of

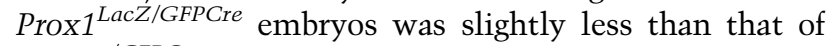
Prox $1^{+/ G F P C r e}$ ECs (Fig. 1A,B, arrows; Supplemental Fig. 4); however, at E11.5, the intensity was dramatically reduced

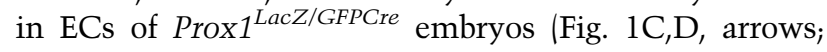


Supplemental Fig. 4). This observation was further confirmed by image analysis software that also revealed that the intensity of PECAM staining (an internal control) was comparable at E10.5, and was only slightly reduced in Prox $1^{\text {LacZ/GFPCre }}$ embryos at E11.5 (Fig. 1E).

Finally, to follow the fate of the Prox1-null ECs, we crossed Prox $1^{+/ G F P C r e}$ and Prox $1^{+/ f} ;$ R26R (Harvey et al. 2005) mice to generate Prox $1^{f / G F P C r e}$;R26R embryos and analyzed them at E11.5. As mentioned before, at this stage, $\mathrm{GFP}^{+} \beta$-gal ${ }^{+} \mathrm{PECAM}^{+}$cells can be detected in and around the anterior cardinal vein of Prox $^{+/ G F P C r e} ; R 26 R$ embryos (Fig. 1F, arrows). In Prox $1^{f / G F P C r e}$;R26R littermates, the level of GFP expression was reduced in many ECs (Fig. 1G, arrows), and $\mathrm{GFP}^{-} \beta$-gal ${ }^{+} \mathrm{PECAM}^{+}$cells could be seen on and around the anterior cardinal vein (Fig. 1G, arrowheads). This result confirms that GFP expression is turned off in Prox1-null ECs. In addition, it indicates the existence of two phases of LEC development-an early phase during which Prox1 expression is initiated in venous LEC progenitors, and a

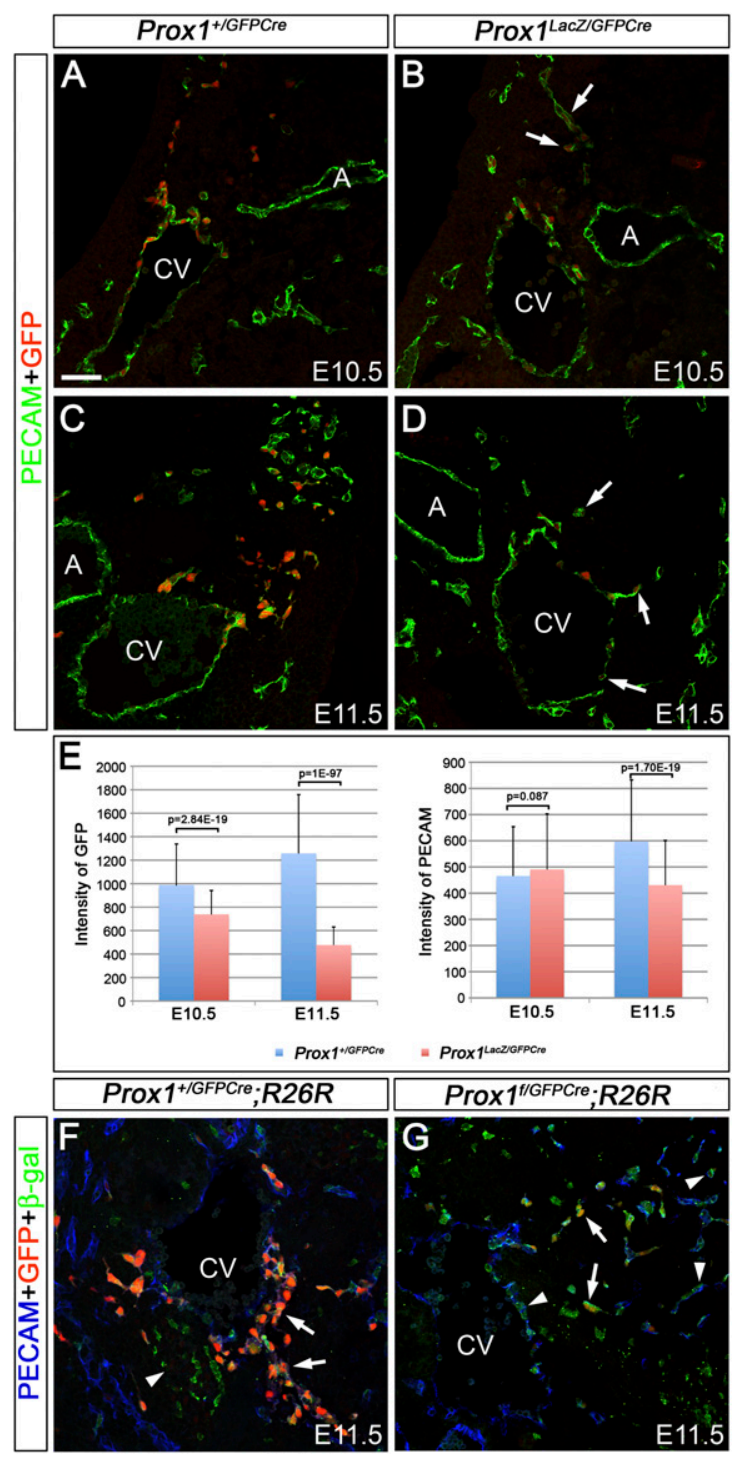

later phase during which Prox1 expression becomes dependent on the presence of Prox1.

\section{Coup-TFII is a direct activator of Prox1 in the embryonic veins}

As discussed above, Sox18 is an upstream regulator of Prox1 expression in venous LEC progenitors (Francois et al. 2008); however, this gene's activity alone is not sufficient to induce Prox1 expression in arterial ECs. Therefore, some other factor might cooperate with Sox18 during the initial induction of Prox1 expression in venous ECs, and Coup-TFII is a potential candidate.

We showed previously that LEC specification is defective in E10.5 Tie2-Cre;Coup-TFII/f mutant mouse embryos in which venous identity is suppressed (You et al. 2005; Srinivasan et al. 2007). Accordingly, we analyzed these mutant embryos in further detail to identify the mechanisms that control the initiation of Prox1 expression in venous LEC progenitors. One possible argument that explains this phenotype is that the deletion of Coup-TFII affected the expression of Sox 18 and, therefore, that of Proxl. However, this was not the case. The expression of Sox18 mRNA appeared to be unaffected in the embryonic veins of E10.5 Tie2-Cre; Coup-TFII ${ }^{f / f}$ mutant embryos (Supplemental Fig. 5).

Coup-TFII expression in veins is required to promote venous identity by inhibiting Notch signaling, and the loss of Coup-TFII function in Tie2-Cre;Coup-TFII ${ }^{f / f}$ embryos results in the ectopic expression of Notch1 in veins and the consequent dedifferentiation of these cells to an arterial fate (You et al. 2005). Thus, another possible explanation for the defective LEC specification phenotype observed in Tie2-Cre;Coup-TFII/f mutant embryos is that ectopic Notch signaling suppresses Prox1 expression. To test this possibility, we attempted to rescue the

Figure 1. Maintenance of Prox1 expression in LECs requires Prox1. $(A, B)$ Compared with that in E10.5 Prox $1^{+/ G F P C r e} \mathrm{em}-$

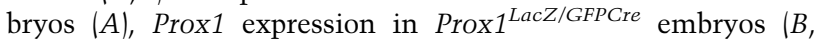
arrows) is moderately reduced in the ECs migrating from the anterior cardinal vein $(\mathrm{CV})$, as indicated by immunostaining for GFP (red). $(C, D)$ At E11.5, the level of GFP expression remains high in the LECs of Prox $1^{+/ G F P C r e}$ embryos $(C)$, whereas it is down-regulated in the Prox1-null ECs of Prox $1^{\text {LacZ/GFPCre }}$ littermates $\left(D\right.$, arrows). (E) Image analysis was performed on $\mathrm{GFP}^{+}$cells from eight identical level sections for each embryo. At E10.5, quantification of GFP and PECAM intensities indicates a moderate reduction in GFP expression in the ECs of Prox $1^{\text {LacZ/GFPCre }}$ embryos; PECAM levels appear comparable. At E11.5, the GFP level is markedly reduced in Prox $1^{\text {LacZ/GFPCre }}$ ECs. PECAM expression is only moderately reduced in Prox1-null ECs. $(F)$ At E11.5, $\mathrm{GFP}^{+} \mathrm{PECAM}^{+} \beta$-gal ${ }^{+}$cells line the cardinal vein and migrate from it in Prox $1^{+/ G F P C r e} ; R 26 R$ embryos (arrows). A few mesenchymal cells weakly express GFP. Correspondingly, these cells are also $\beta$-gal ${ }^{+}$(arrowhead). (G) GFP expression is weak in numerous $\beta$-gal ${ }^{+} \mathrm{PECAM}^{+}$cells of E11.5 Prox $^{\text {f/GFPCre }} ; R 26 R$ embryos (arrows). Numerous GFP ${ }^{-} \mathrm{PECAM}^{+} \beta-$ gal $^{+}$cells are also located on and outside the cardinal vein (arrowhead). The neural tube is oriented toward the top of $A-D$ and toward the right side in $F$ and $G$. (CV) Anterior cardinal vein; (LS) lymph sacs; (A) dorsal aorta. Bar, $50 \mu \mathrm{m}$. 
loss of Prox $1^{+}$LECs by deleting $R b p j$, the primary mediator of Notch signaling (Kato et al. 1997; Tanigaki et al. 2002), from venous ECs. To this end, E10.0 Tie2Cre;Coup-TFII ${ }^{f / f}$, Tie2-Cre;Rbpifff, and Tie2-Cre;Coup$T^{T F I I^{f / f}} ; R b p i^{f / f}$ embryos were generated and analyzed. We bred Tie2-Cre;Coup-TFII ${ }^{+/ f}$; $b p j^{+/ f}$ mice with each other, and from 17 litters we obtained 173 E10.0 embryos. Of those, 21 were Tie2-Cre;Coup-TFII f/f , which is in the expected Mendelian ratio (one out of eight); however, we collected only three Tie2-Cre;Rbpif/f and two Tie2Cre;Coup-TFII ${ }^{f / f} ; \mathrm{Rbpj}^{f / f}$ embryos. This indicates that the absence of Notch signaling affects the survival of the embryos at a much earlier time point. We analyzed two embryos from each of the genotypes. As expected, the expression of the arterial-specific marker connexin 40 (CX40) (Delorme et al. 1997) was restricted to the arteries of control embryos (Supplemental Fig. 6A,B). Consistent with the role of Notch signaling in the maintenance of arterial identity (Krebs et al. 2004), CX40 expression was lost in the arteries of Tie2-Cre;Rbpif/f embryos (Supplemental Fig. 6D,E). In Tie2-Cre;Coup-TFII $/ f$ embryos, in addition to the normal CX40 expression in arteries (Supplemental Fig. 6G,H, arrowheads), ectopic expression was detected in certain restricted regions of the mutant veins (Supplemental Fig. 6G,H, arrows) that seem to also contain abnormal arterio-venous shunts (AVM) (Supplemental Fig. $6 \mathrm{H}$, red arrow). As expected, in Tie2Cre;Rbpif/f; Coup-TFII ${ }^{f / f}$ embryos, CX40 expression remained dramatically reduced in arteries (Supplemental Fig. 6J,K). Importantly, we did not observe ectopic expression of CX40 in the mutant veins (Supplemental Fig. $6 \mathrm{~J}, \mathrm{~K})$, indicating that the loss of $R b p j$ at least partially rescued the venous identity in Tie2-Cre;Coup-TFII ${ }^{f / f}$ embryos.

Next, immunohistochemistry against Prox1 and Lyve1 revealed that their expression was normal in control and Tie2-Cre;Rbpif/f embryos (Supplemental Fig. 6C,F), a result indicating that Notch signaling is not required for LEC specification. As reported previously (Srinivasan et al. 2007), the number of Prox1-expressing LECs was dramatically reduced in Tie2-Cre;Coup-TFII ${ }^{f / f}$ embryos (Supplemental Fig. 6I). In Tie2-Cre;Coup-TFII ${ }^{f / f}$;Rbpiff embryos, the number of Prox1-expressing LECs remained dramatically reduced (Supplemental Fig. 6L).

Together, these results indicate that the loss of venous identity, but not that of LECs, can be rescued in Tie2-Cre;Coup-TFII f/f embryos upon removal of ectopic Notch signaling from the mutant venous ECs. They also suggest that, in addition to suppressing Notch signaling, Coup-TFII activity is required during LEC specification. Furthermore, only one-fifth of the number of LECs detected in control embryos were counted in E10.5 Tie2-Cre;Coup-TFII f/f embryos (Srinivasan et al. 2007), and these LECs were also Coup-TFII ${ }^{+}$(Supplemental Fig. 7). This result indicates a cell-autonomous requirement for Coup-TFII in LEC specification, and suggests that, in that process, Coup-TFII activity lies upstream of Prox1.

To investigate whether Coup-TFII directly regulates Proxl expression, we first used the TRANSFAC Bioinformatics program (Matys et al. 2006) to search for putative
Coup-TFII DNA-binding motifs (CBS) (Fig. 2A) in putative regulatory regions of available Prox1 genomic sequences from humans, chimpanzees, mice, and rats. The regions were located $5 \mathrm{~kb}$ upstream of the noncoding exon 1 and in intron 1 . We identified two putative Coup-TFIIbinding sites in mice and rats, five in chimpanzees, and six in humans (Fig. 2B). Interestingly, the binding site located $\sim 9.5 \mathrm{~kb}$ upstream of the ORF of mouse Prox 1 is conserved among the four mammals (Fig. 2B, red circles). Furthermore, by performing multiple sequence alignment, we found that this sequence is also conserved among other mammals whose genomic sequences are available (Fig. 2C).

To determine whether the conserved recognition motif identified in the mouse behaves as a Coup-TFII-binding site, we amplified a 201-base-pair (bp) DNA fragment containing this motif and performed electrophoretic mobility shift assays (EMSA) using 293T cells transfected with a COUP-TFII expression plasmid. The radiolabeled probe containing the conserved Coup-TFII-binding site shifted only slightly in control cell lysates (Fig. 2D, lane 2), a result that may have been caused by endogenous COUP-TFII (see below); in contrast, the cell lysates in which COUP-TFII was expressed ectopically showed a strong band shift (Fig. 2D, lane 3). Migration of the labeled probe was further retarded upon addition of a monoclonal antibody against COUP-TFII (Fig. 2D, lane 4), indicating that the shift and the supershift were specific to COUP-TFII binding to the probe. The binding specificity was further confirmed by the reduced amount of complex that formed when 250-fold excess of nonradioactive probe was added (Fig. $2 \mathrm{D}$, lane 5 ), and by the fact that this competition was less efficient when two of the highly conserved TG residues present in the CoupTFII-binding site were mutated to AA residues in the nonradioactive probe (Fig. 2D, lane 6). No specific binding was detected when we repeated the EMSA assay using a probe for a nonconserved putative Coup-TFII-binding site (data not shown).

Next, we performed chromatin immunoprecipitation (ChIP) analysis on isolated human LECs by using a rabbit polyclonal antibody specific for COUP-TFII and TaqManbased real-time PCR. Using this approach, we detected a significant $(P \leq 0.01)$ enrichment when amplifying the identified conserved COUP-TFII-binding site in comparison with a nonconserved COUP-TFII-binding site or a region located $40 \mathrm{~kb}$ downstream from the ATG (Fig. 2E).

We further confirmed this transcriptional regulation by performing a luciferase assay. Briefly, six conserved CoupTFII-binding sites were inserted in tandem into the pGL3 basic luciferase reporter plasmid (6XCBS). Two additional versions of this reporter were generated by mutating 4 or 8 conserved nucleotides in each of the 16-nucleotide (nt) CBS repeats (6XmCBS1 and $6 \mathrm{XmCBS} 2$, respectively). 293 T cells were then transfected with either of these reporter plasmids, with or without a COUP-TFII-expressing plasmid. Small amounts of COUP-TFII are expressed endogenously by $293 \mathrm{~T}$ and NIH $3 \mathrm{~T} 3$ cell lines (Fig. 2F). Cells into which only the 6XCBS reporter plasmid was transfected showed higher luciferase reporter activity 
than those containing the pGL3 basic control plasmid (Fig. 2G). This activity increased when the cells were cotransfected with increasing concentrations of COUPTFII expression plasmid (Fig. 2G). In contrast, cells that were transfected with the $6 \mathrm{XmCBS} 1$ reporter plasmid with or without the COUP-TFII expression plasmid showed significantly less activity than cells transfected with the 6XCBS plasmid (Fig. 2G). The activity of the $6 \mathrm{XmCBS} 2$ plasmid was at a basal level and comparable with that of the control plasmid (Fig. 2G). Together, these results argue that Coup-TFII binds to the identified conserved site located in the Prox1 regulatory region, and is a direct in vivo regulator of Prox 1 expression in

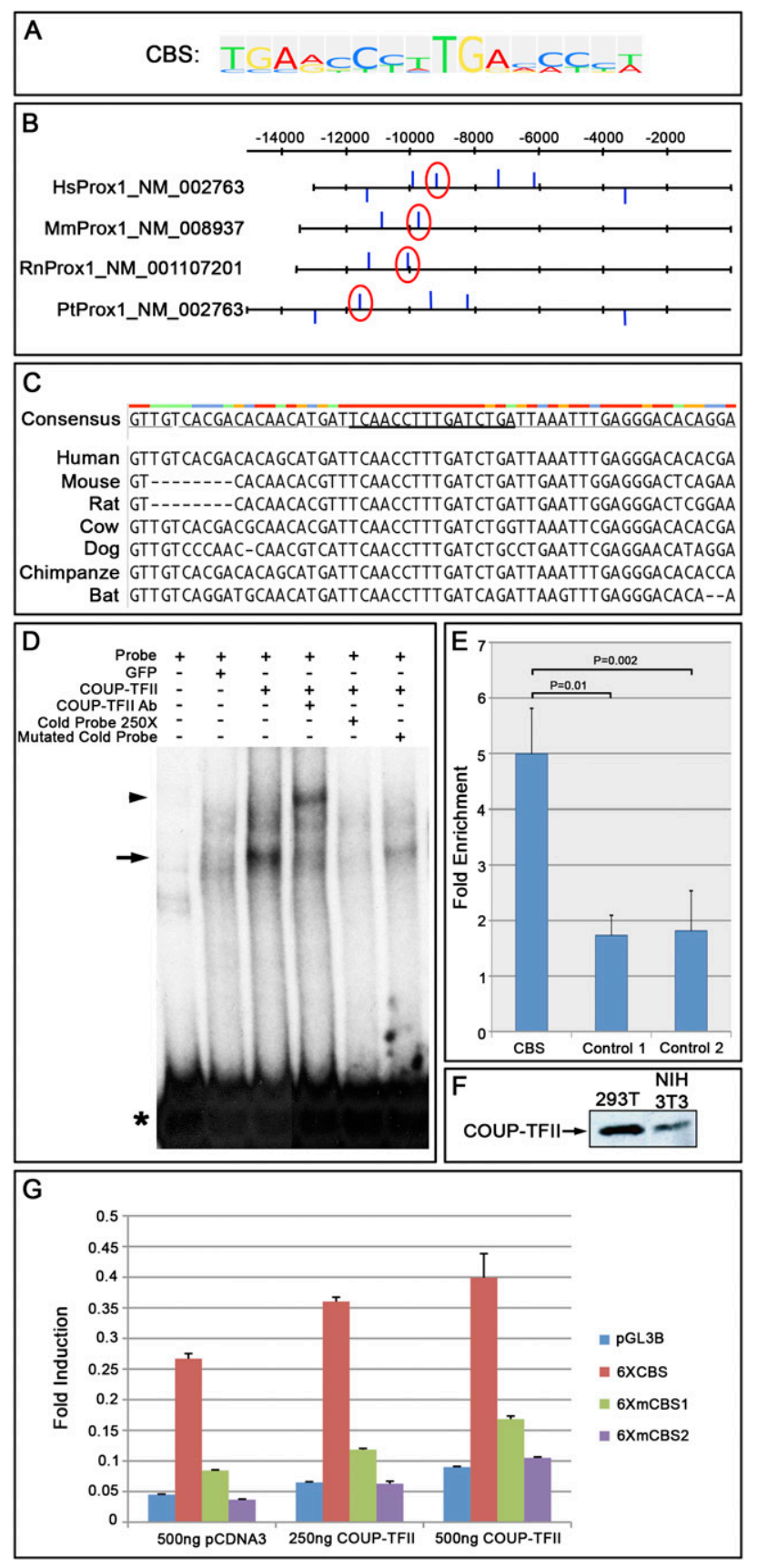

venous LEC progenitors during the early phases of LEC specification.

\section{Coup-TFII is required to maintain Prox1 expression during the early phase of LEC specification}

Prox1 expression in the developing lymphatic vasculature occurs in two separate phases: an initiation phase, and a Prox1-dependent maintenance phase. We established here that Coup-TFII plays an early role in the initiation of Proxl expression in venous LEC progenitors. Results from ECs maintained in culture suggest that Coup-TFII activity also maintains the LEC phenotype by

Figure 2. Coup-TFII binds directly to a conserved site present in the Prox1 upstream regulatory region. $(A)$ Coup-TFII recognizes a 16-nt motif (CBS) that consists of two similar 8-nt repeats. $(B)$ A DNA region located $5 \mathrm{~kb}$ upstream of the noncoding exon 1 and the entire intron 1 (upstream of the ATG translational start codon) of human (Hs), mouse (Mm), rat $(\mathrm{Rn})$, and chimpanzee $(\mathrm{Pt})$ Prox1 was analyzed, and putative CBSs were identified (blue bars). Upward bars indicate those in the sense orientation, and downward bars indicate those in the antisense orientation. Red circles highlight the CBS that is conserved among all species tested. $(C)$ The identified CBS is also conserved among other mammals whose DNA sequences are available. The consensus DNA sequence is underlined. The colors above the nucleotides indicate the consensus strength, with red being the strongest and blue being the weakest. $(D)$ The conserved CBS from the mouse Prox1 gene was amplified by $\mathrm{PCR}$, and the radiolabeled probe was generated using ${ }^{32} \mathrm{P}$-dCTP. EMSA was performed using 293T cell lysates with or without ectopically expressed COUP-TFII. (Lane 1) Probe alone (asterisk). (Lane 2) Labeled probe incubated with GFP-transfected 293 T cell lysate. (Lane 3) Labeled probe incubated with COUPTFII-transfected 293T cell lysate. The shift in the mobility of the probe is seen (arrow). (Lane 4) Probe incubated with COUP-TFIItransfected $293 \mathrm{~T}$ cell lysate and a mouse monoclonal antibody against COUP-TFII. A supershifted band (arrowhead) can be seen. (Lane 5) An excess (250-fold) of nonradiolabeled probe efficiently competed with the binding of COUP-TFII to the radiolabeled probe. (Lane 6) Replacement of the two highly conserved TG residues by AA residues in the nonradiolabeled probe reduced this competition. $(E)$ ChIP was performed on human LECs maintained in culture by using a rabbit polyclonal antibody against COUP-TFII. Real-time PCR was carried out using the pulled-down DNA fragment as a template and primers and probes specific for the conserved CBS, a nonconserved CBS (control 1), or a nonspecific site $40 \mathrm{~kb}$ downstream from the ATG (control 2). When compared with controls, a statistically significant $(P \leq 0.01)$ enrichment was observed for the conserved CBS. $(F)$ Western blotting shows the expression of COUPTFII in 293T and NIH 3T3 cells commonly used for luciferase assays. (G) Dual luciferase assay was carried out using the generated reporters containing six consecutive conserved CBSs that are wild-type (6XCBS), carrying a mutation in 4 of the $16 \mathrm{nt}$ (6XmCBS1), or carrying a mutation in 8 of the $16 \mathrm{nt}$ (6XmCBS2). The 6XCBS showed endogenous activity caused by the presence of COUP-TFII in the cells. This activity increased with increasing concentrations of the COUP-TFII expression plasmid. Although the 6XmCBS1 showed reduced endogenous activity, it moderately responded to ectopic COUP-TFII. The 6XmCBS2 did not show any endogenous activity and did not respond to COUP-TFII. 
interacting with Prox1 (Lee et al. 2009; Yamazaki et al. 2009). To assess whether Coup-TFII is required to maintain the LEC phenotype in vivo, we first performed a detailed analysis of Coup-TFII expression in developing lymphatics by using a Coup-TFI-specific antibody with antibodies against Prox1 or Lyve1 (Supplemental Fig. 8A,C, E). We also took advantage of the fact that conditional deletion of Coup-TFII activates a lacZ reporter only in those tissues where the gene was deleted (Takamoto et al. 2005; You et al. 2005). Thus, we bred Prox $1^{+/ C r e E R T 2}$ mice (Srinivasan et al. 2007) with Coup-TFII ${ }^{+/ f}$ mice (Takamoto et al. 2005) and exposed the double-heterozygous animals to tamoxifen (TM) at different time points to activate the lac $Z$ reporter (Supplemental Fig. 8B,D,F). In agreement with a previous study (Lee et al. 2009), Coup-TFII was coexpressed with Proxl in E11.5 LECs located in and around the cardinal vein (Supplemental Fig. 8A). By X-gal and Proxl costaining (Supplemental Fig. 8B), or by immunostaining with the LEC marker Lyve1 (Supplemental Fig. $8 \mathrm{C}$ ), we also detected Coup-TFII expression in the lymph sacs at E12.5 and E14.5, respectively. Whole-mount X-gal staining of E15.5 Prox ${ }^{+/ C r e E R T 2}$;Coup-TFII ${ }^{+/ f}$ embryos exposed to TM at E10.5 showed that Coup-TFII is expressed in the peripheral lymphatics of these embryos (Supplemental Fig. 8D). At E16.5, coimmunostaining for CoupTFII, Prox1, and Lyve1 showed that Coup-TFII is expressed in the Prox $1^{+}$Lyve $1^{+}$lymphatic vessels near the pericardial cavity (Supplemental Fig. 8E). Finally, whole-mount X-gal staining of the ears of P15 Prox $1^{+/ C r e E R T 2}$;Coup-TFII ${ }^{+/ f}$ pups exposed to TM between P1 and P10 showed that CoupTFII is expressed in the dermal lymphatics (Supplemental Fig. 8F).

To identify possible functional roles of Coup-TFII in developing lymphatics once Proxl expression in LEC progenitors has already been initiated, we first generated Prox $1^{+/ G F P C r e}$;Coup-TFII ${ }^{+/ f}$ mice by crossing Prox $1^{+/ G F P C r e}$ with Coup-TFII ${ }^{+/ f}$ mice. From those crosses, which resulted in nearly 400 pups, only $10 \%$ were Prox $1^{+/ G F P C r e}$, and $2.5 \%$ were Prox $1^{+/ G F P C r e}$;Coup-TFII ${ }^{+/ f}$. This reduced number of Prox $1^{+/ G F P C r e}$;Coup-TFII ${ }^{+/ f}$ mice may have been caused by a cooperative effect between Proxl and Coup-TFII in normal development. We then generated Prox ${ }^{+/ G F P C r e} ;$ Coup-TFII ${ }^{\Delta / f}$ embryos by crossing Prox $^{+/ \text {GFPCre }}$;Coup-TFII ${ }^{+/ f}$ mice with Coup-TFII ${ }^{+/ f}$ or Coup-TFII $I^{f / f}$ mice, and analyzed at least three mutant embryos from independent crosses at each stage. Normally, at E11.5, strong Proxl expression is detected in the cardinal vein and LECs that start to move away from the cardinal vein (Fig. 3A). However, in Prox $1^{+/ G F P C r e}$;Coup$\mathrm{TFII}^{\Delta / f}$ littermates, very few (if any) weakly Prox1expressing LECs were observed on or outside the cardinal veins (Fig. 3B, arrow). Similarly, at E13.5, the Prox $1^{+}$lymph sacs seen in control embryos (Fig. 3D) were missing in Prox $1^{+/ G F P C r e}$;Coup-TFII ${ }^{\Delta / f}$ littermates (Fig. 3E). Consistently, at E16.5, no Proxl ${ }^{+}$LECs were observed in the dermis, lung, or mesentery of Prox $1^{+/ G F P C r e}$;Coup-TFII ${ }^{\Delta / f}$ embryos (data not shown). The complete absence of LECs observed in Prox $1^{+/ G F P C r e} ;$ Coup-TFII ${ }^{\Delta / f}$ embryos was similar to that seen in Prox $1^{\text {LacZ/GFPCre }}$ embryos. Analysis of Prox $1^{\text {LacZ/GFPCre }}$ embryos showed that Prox1 is required to maintain Prox1 expression (Fig. 1). Because in Prox $1^{+/ G F P C r e}$;Coup-TFII ${ }^{\Delta / f}$ mice Coup-TFII is deleted soon after the initiation of Prox1 expression (once LEC specification has started), we conclude that, in addition to that of Prox1, the activity of Coup-TFII is required for the maintenance of Prox 1 expression in early differentiating LECs.

In this scenario, LECs may have a positive feedback loop in which Coup-TFII activates the expression of Prox1, which in turn maintains Coup-TFII expression. To test this possibility, and to identify the mechanisms by which Coup-TFII and Prox1 cooperate in the maintenance of Prox1 expression, we analyzed Coup-TFII expression in the $\mathrm{GFP}^{+}$cells of E11.0 Prox $1^{\text {GFPCre/GFPCre }}$ embryos. Normal Coup-TFII expression was detected in the $\mathrm{GFP}^{+}$(Prox1-null) ECs (Supplemental Fig. 9A,B), a result indicating that Proxl is not necessary to maintain

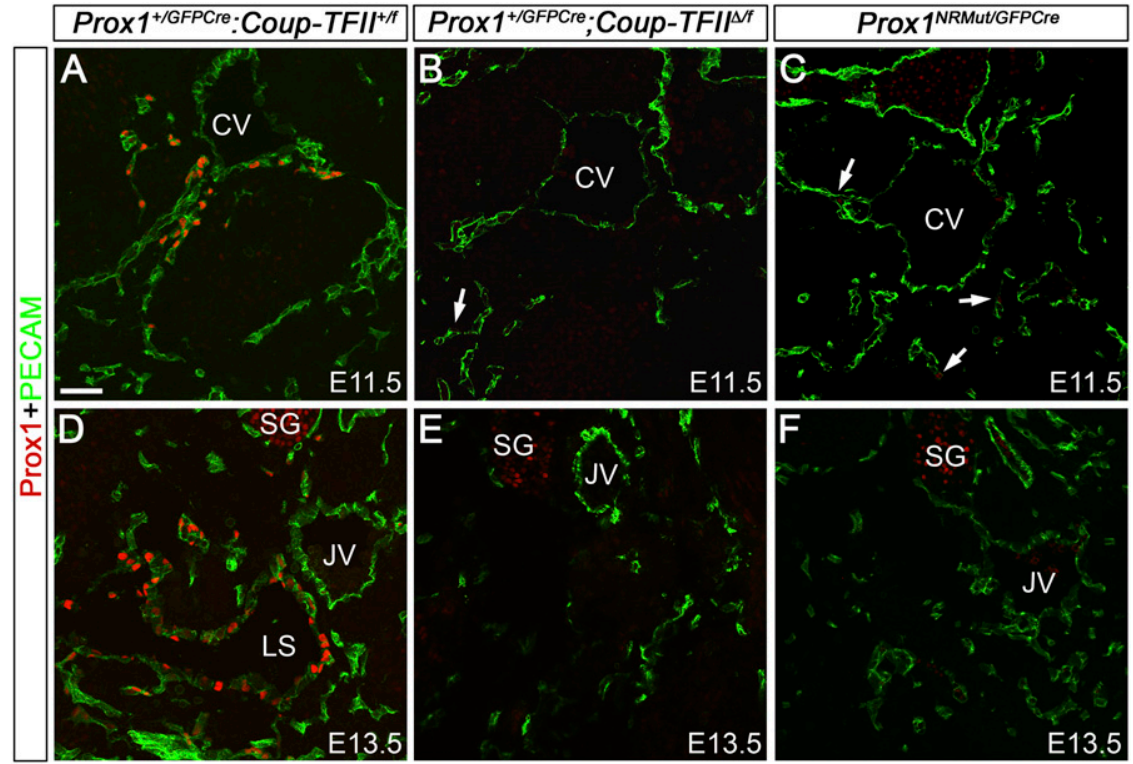

Figure 3. Interaction between Coup-TFII and Prox 1 is required to maintain Prox 1 expression in LECs. (A) At E11.5, Prox1expressing LECs (red) are seen in and around the anterior cardinal vein $(\mathrm{CV})$ of Prox $^{+/ \text {GFPCre }} ;$ Coup-TFII ${ }^{+/ f}$ embryos. (B) Just a few Prox $1^{+}$LECs (arrow) are seen in Prox $1^{+/ G F P C r e}$;Coup-TFII ${ }^{\Delta / f}$ littermates. (C) E11.5 Prox $1^{\text {NRMut/GFPCre }}$ embryos expressing a form of Prox 1 mutated in the nuclear hormone receptor-binding site also have a reduced number of LECs (arrows). (D) At E13.5, the lymph sacs (LS) lined by Prox $1^{+}$LECs are seen in control embryos. However, at this stage, no LECs are seen in Prox $1^{+/ G F P C r e} ;$ Coup-TFII ${ }^{\Delta / f}(E)$ or Prox $1^{\text {NRMut/GFPCre }}(F)$ embryos. PECAM is shown in green. The neural tube is oriented toward the left side of all panels. (JV) Jugular vein; (SG) sympathetic ganglia. Bar, $50 \mu \mathrm{m}$. 
Coup-TFII expression. Another possibility is that Prox1 maintains the expression of Sox18, which cooperates with Coup-TFII to maintain that of Prox1. However, we observed no obvious changes in the expression of Sox18

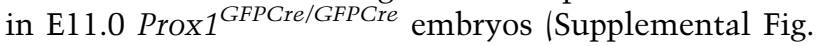
9C-H). These results indicate that, during the LEC specification phase, Coup-TFII and Sox18 are necessary but not sufficient to maintain Prox1 expression, and that Proxl is required during this stage to maintain its own expression.

Previous in vitro studies have suggested a physical interaction between Coup-TFII and Proxl in LECs (Lee et al. 2009; Yamazaki et al. 2009). Therefore, because Proxl and Coup-TFII are required for the maintenance of Prox1 expression, once Coup-TFII initiates Prox1 expression in venous LEC progenitors, they may interact with each other. To test this possibility, we generated a knockin mouse line in which two putative nuclear hormone receptor-binding sites (Liu et al. 2003; Qin et al. 2004; Steffensen et al. 2004; Wang et al. 2008; Lee et al. 2009; Yamazaki et al. 2009) in Proxl were mutated (Prox $1^{+/ N R M u t}$ ) (Supplemental Fig. 10). This mutated version of Prox1 contained a synthetic tag (avitag) (Supplemental Fig. 10). Similar to wild-type Prox1, avitag-containing wild-type Proxl was also capable of activating the expression of LECspecific markers when expressed ectopically in blood ECs maintained in culture (Supplemental Fig. 11). This result indicates that the inclusion of the avitag did not affect Proxl activity. Unlike Prox $1^{+/ L a c Z}$, Prox $1^{+/ N R M u t}$ embryos did not exhibit any obvious edema at E15.5 (Supplemental Fig. 12A,B), and Prox $1^{+/ N R M u t}$ pups were born at normal Mendelian ratios (data not shown). These results indicate that the mutation of the nuclear hormone-binding site did not completely abolish Proxl activity. Analysis of

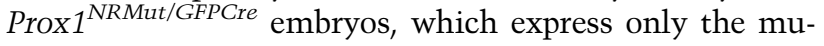
tant form of Prox1, revealed the presence of a few scattered weakly Prox1-expressing LECs at E11.5 (Fig. 3C, arrows) and none at E13.5 (Fig. 3F). Analysis of sections along the anteroposterior axis of E11.5 Prox $1^{+/ G F P C r e}$, Prox $1^{+/ G F P C r e}$; Coup-TFII $^{\Delta / f}$, and Prox $1^{\text {NRMut/GFPCre embryos identified }}$ only a few Prox $1^{+}$LECs in the last two mutant strains (Supplemental Fig. 13).

Next, we analyzed the generated Prox $1^{\text {NRMut/NRMut }}$ embryos. Contrary to their heterozygous littermates, the homozygous embryos exhibited severe edema at E13.5 (Supplemental Fig. 12C,D). Comparison of transverse section at the level the jugular lymph sacs of control (Supplemental Fig. 12E) and Prox $1^{\text {NRMut/NRMut }}$ (Supplemental Fig. $12 \mathrm{~F}$ ) embryos showed a significant reduction in the number of Prox $1^{+}$LECs in the mutant embryos. These mutant LECs did not express the normal levels of other LEC markers, such as Nrp2 and Lyve1 (Supplemental Fig. 12F, arrow). Furthermore, serial sectioning along the anteroposterior axis of these mutant embryos revealed the presence of only a few Prox $1^{+}$LECs that abnormally aggregated around the jugular vein (Supplemental Fig. 12G-J).

The phenotype observed in Prox $1^{\text {NRMut/GFPCre }}$ embryos

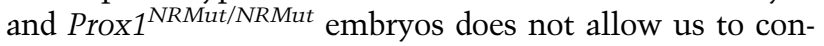
clude whether this phenotype is caused by the loss of interaction between Proxl and Coup-TFII or because in- teraction of Prox 1 with other nuclear hormone receptors is required to regulate Prox1 expression. However, the phenotypic similarity of Prox $1^{\text {NRMut/NRMut }}$ and Prox $1^{\text {NRMut/GFPCre }}$ embryos with that of Prox $1^{+/ G F P C r e}$;Coup-TFII ${ }^{\Delta / f}$ embryos strongly suggested that the Coup-TFI-Proxl interaction is necessary to maintain Prox1 expression and, therefore, LEC identity during the LEC specification stage.

\section{Prox1 expression in specified LECs is independent of Coup-TFII expression}

Similar to Proxl expression, that of Coup-TFII in LECs is maintained throughout embryonic and postnatal stages; therefore, we tested whether Coup-TFII activity was constantly required to maintain Prox1 expression in LECs during developmental lymphangiogenesis. To do this, we took advantage of the previously generated TMinducible Prox $1^{+/ C r e E R T 2}$ mouse strain (Srinivasan et al. 2007). We exposed Prox $1^{+/ C r e E R T 2}$; Coup-TFII ${ }^{+/ f}$ and Prox ${ }^{+/ C r e E R T 2}$;Coup-TFII ${ }^{\mathrm{f} / \mathrm{f}}$ embryos to TM $(5 \mathrm{mg} / 40 \mathrm{~g}$ body weight of the pregnant dams) at various developmental time points (E10.5-E14.5) and analyzed them at E15.5. The most representative from at least three independent crosses is presented. Prox $1^{+/ C r e E R T 2}$;Coup-TFIf ${ }^{f / f}$ embryos exposed to TM at E10.5-E12.5 exhibited edema and bloodfilled dermal vessels (Fig. 4B-D).

Conditional deletion of Coup-TFII activated the lacZ reporter wherever the gene was deleted. Accordingly, wholemount staining performed in the Prox $1^{+/ \text {CreERT2 }}$;Coup-TFII $/$ /f conditional mutant embryos showed a reduced number of $\mathrm{X}$-gal-stained superficial vessels; the earlier the embryos were exposed to TM, the more severe the reduction (Fig. 4F-H). Analysis of Prox $1^{+/ C r e E R T 2}$; Coup-TFII ${ }^{f / f}$ embryos exposed to TM at E10.5 or E11.5 showed that the expression of LEC markers in regions with few $\beta$-gal ${ }^{+}$vessels was either completely absent or severely reduced, thereby confirming that the lack of X-gal staining indicates a lack of lymphatic vessels (Supplemental Fig. 14). Further analysis showed that the lymph sacs of these conditional mutant embryos were also drastically mispatterned and reduced in size (Supplemental Fig. 14B, arrow). Sectioning of Prox $1^{+/ \text {CreERT2 }}$;Coup-TFII ${ }^{f / f}$ embryos exposed to TM at E12.5 revealed a substantial reduction in the expression of the LEC markers Nrp2, Lyve1, and podoplanin in these blood-filled lymphatic vessels, although Proxl levels appeared normal (Fig. 5). We also immunostained for Proxl and Coup-TFII or $\beta$-gal to determine whether the remaining Prox $1^{+}$LECs are the result of incomplete deletion of Coup-TFII. Expression of this gene was markedly reduced or completely absent in the surviving Prox $1^{+}$cells (Fig. 6), thereby excluding this possibility.

In contrast to the phenotypic alterations observed upon early TM administration (E10.5-E12.5), few $(<10 \%$ ) PrOX $^{+/ C r e E R T 2}$; Coup-TFIf ${ }^{f / f}$ embryos displayed lymphatic reduction or lymphatic defects when exposed to TM at E13.5, and no obvious lymphatic vascular defects were observed when TM was administered at later developmental or postnatal time points (see below; data not shown). For example, Prox $1^{+/ C r e E R T 2}$; Coup-TFII/f embryos and their control littermates were exposed to TM at E14.5 and E15.5, and the phenotypically normal embryos were 


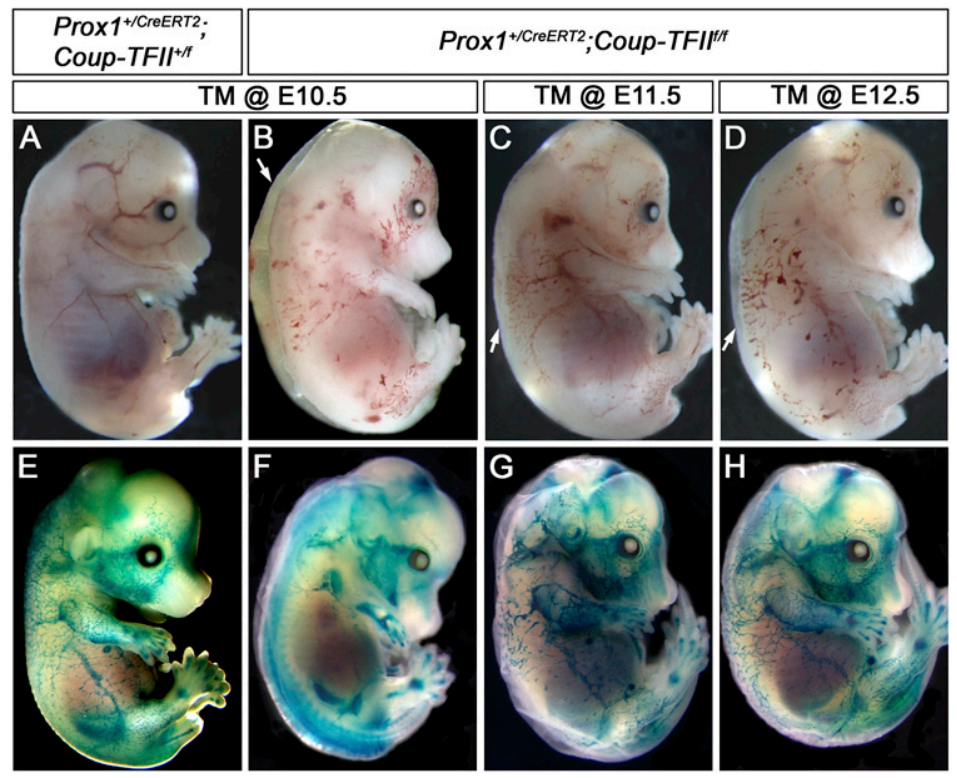

Figure 4. Coup-TFII has a time-dependent role in the regulation of lymphatic vascular development. $(A-D)$ ${\text { PrOX } 1^{+/ C r e E R T 2} \text {;Coup-TFII }}^{+/ f}(A)$ and Prox $1^{+/ \text {CreERT2 }}$;CoupTFIf $^{f / f}(B-D)$ embryos were exposed to TM at the indicated time points and isolated at E15.5. Blood-filled superficial vessels and edema (arrows) are observed in Prox ${ }^{+/ C r e E R T 2}$; Coup-TFII $I^{f / f}$ embryos. $(E-H)$ The above embryos were wholemount X-gal-stained for $\beta$-gal activity. $(E)$ The X-gal ${ }^{+}$LECs are seen forming the dermal lymphatic plexus in control embryos. (F) In contrast, in Prox $1^{+/ \text {CreERT2 }}$;Coup-TFII ${ }^{f / f}$ embryos exposed to TM at E10.5, the superficial lymphatic plexus is nearly absent. $(G, H)$ The number of superficial X-gal ${ }^{+}$cells increases concomitantly with the later time of TM exposure. However, the overall size of the lymphatic plexus remains smaller than that of control embryos. analyzed at E16.5 by either X-gal staining or immunostaining of sections with antibodies against Proxl and Coup-TFII. The X-gal staining confirmed efficient deletion of Coup-TFII in the superficial lymphatics, and the immunostaining showed a substantial reduction in the expression of Coup-TFII in LECs (Supplemental Fig. 15). These results indicate that Coup-TFII function is not required after E13.5, and that the maintenance of Proxl expression becomes independent of Coup-TFII at this stage.

\section{Discussion}

Previous work identified Sox18 as an upstream regulator of Prox1 expression in the anterior cardinal vein (Francois et al. 2008). However, Proxl expression is not induced in embryonic arteries that also express Sox18. One possible explanation is that some arterial-specific gene (e.g., Notch pathway or Sox18) represses Proxl induction. Another possible explanation is that, in veins, some other factors cooperate with Sox18 in the induction of Prox1. On the basis of our results, we propose that Coup-TFII is at least one of these factors.

We determined that, during LEC differentiation, three phases of Proxl regulation are associated with the progress of the stepwise process leading to LEC differentiation (Fig. 7). Here we demonstrated that Coup-TFII activity is necessary for the direct activation of Prox 1 expression in venous LEC progenitors. However, the few days of delay between the appearance of Coup-TFII-expressing veins and the detection of the first Prox1-expressing LECs argues that venous fate and, therefore, Coup-TFII expression, although necessary, are not sufficient to initiate LEC differentiation, and that other factors might be required. Therefore, we speculate that the initial phase of Prox1 induction requires the cooperative activity of Coup-TFII and Sox18.

The second phase of Prox1 regulation occurs once Proxl expression is induced and LEC specification is progressing (Fig. 7). During this phase, the Coup-TFI-
Proxl interaction is required to maintain Prox 1 expression in early differentiating LECs. The third phase is a maintenance phase that depends on Proxl but not Coup-TFII. ChIP analysis failed to identify specific binding of Prox 1 to the identified conserved Coup-TFIIbinding site (data not shown). After transient interaction with Coup-TFII, Prox1 may be recruited to a different site located in its own promoter and regulate its own expression. Alternatively, the Coup-TFII-Prox1 complex may activate another transcription factor that, in turn, regulates Prox1 expression. Both of these possibilities are highlighted in our model (Fig. 7).

Although Coup-TFII is expressed in LECs at all time points, and most likely continues to interact with Prox1 (Lee et al. 2009; Yamazaki et al. 2009), the functional significance of this interaction appears to become subtle after E13.5. It will be interesting to determine whether this interaction has any significant role in conditions such as cancer- or inflammation-induced lymphangiogenesis or wound healing.

Finally, in humans, COUP-TFII maps to chromosome $15 q 25$, a region associated with the autosomal-recessive lymphedema-cholestasis syndrome (also known as Aagenaes syndrome) (Bull et al. 2000). Coup-TFII also regulates metabolism (Li et al. 2009); therefore, this gene may be affected in patients with Aagenaes syndrome. Linkage analysis has shown that the mutation in these patients is present in a $6 \mathrm{cM}$ genomic region in 15q25 (Bull et al. 2000) that is $\sim 3 \mathrm{Mb}$ from the coding region of COUP-TFII. However, Aagenaes syndrome is autosomal-recessive and genetically heterogeneous (Fruhwirth et al. 2003); mutations in the coding region of COUP-TFII most likely result in embryonic lethality; therefore, a reduction in the levels of COUP-TFII expression may cause Aagenaes syndrome. Consistent with this hypothesis, we occasionally observed edema in Coup-TFII f/f mouse embryos (Supplemental Fig. 16), indicating that hypomorphic mutations in COUPTFII might result in lymphatic defects. 


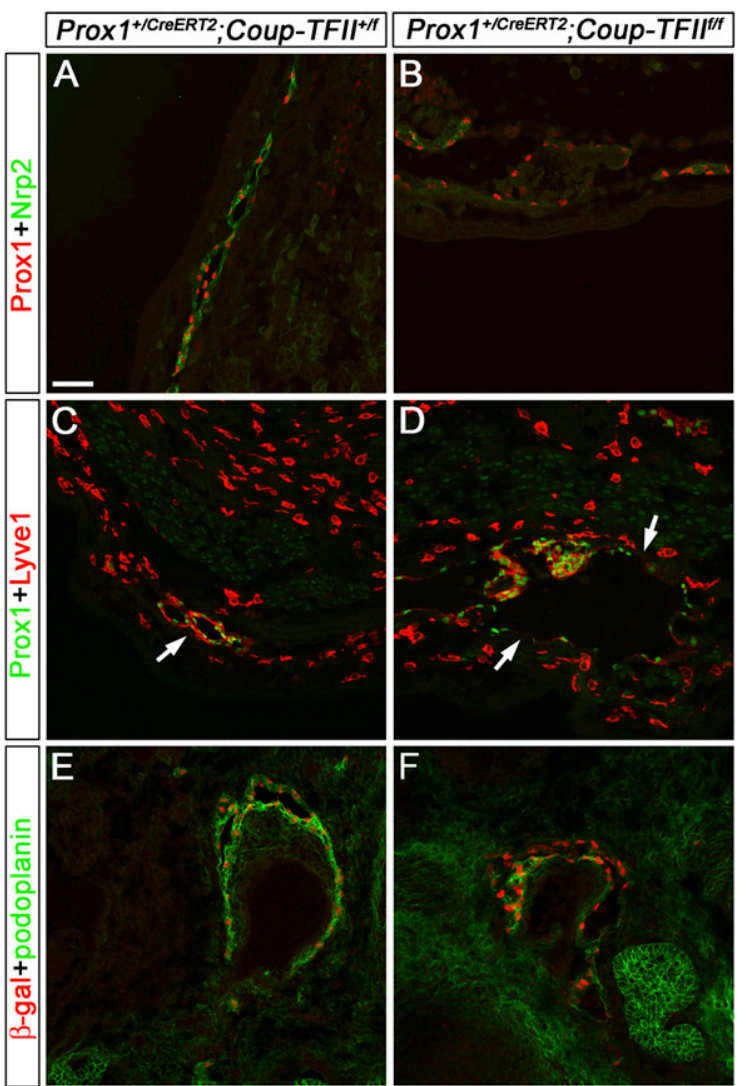

Figure 5. Conditional deletion of CoupTFII using Prox $1^{+/ C r e E R T 2}$ reduces the expression of LEC markers. Prox1 ${ }^{+/ C r e E R T 2}$; CoupTFII $^{+/ f}$ and Prox $1^{+/ C r e E R T 2}$;CoupTFII ${ }^{f / f}$ embryos were exposed to $5 \mathrm{mg}$ TM at E12.5 and were analyzed at E15.5 by immunostaining of sections with different LEC markers. (A) Prox1 (red) and Nrp2 (green) are coexpressed in the LECs of a peripheral lymphatic vessel of Prox $1^{+/ \text {CreERT2 }}$;CoupTFII ${ }^{+/ f}$ embryos. (B) However, in Prox $1^{+/ \text {CreERT2 }}$;CoupTFII ${ }^{f / f}$ embryos, these vessels are dilated and mispatterned, and the expression of Nrp2 is substantially reduced. (C) Proxl (green) and Lyve1 (red) are coexpressed in the peripheral lymphatic vessel (arrow) of Prox $1^{+/ C r e E R T 2}$;CoupTFII ${ }^{+/ f}$ embryos. (D) In contrast, the lymphatic vessels of Prox ${ }^{+/ C r e E R T 2}$;CoupTFII ${ }^{f / f}$ embryos are dilated, and Lyve1 expression is down-regulated in the Prox $1^{+}$LECs of the peripheral lymphatic vessels (arrows). The scattered Prox $1^{-}$Lyve $1^{+}$cells are macrophages. $(E, F)$ Deletion of the floxed Coup-TFII allele results in the activation of the LacZ reporter gene that expresses $\beta$-gal (red). (E) Costaining with the LEC marker podoplanin (green) shows that these markers are coexpressed in the lymphatic vessels of $\operatorname{Prox} 1^{+/ C r e E R T 2}$;COupTFII ${ }^{+/ f}$ embryos. (F) In contrast, the expression of podoplanin is substantially reduced in the lymphatic vessels of $\operatorname{Prox} 1^{+/ C r e E R T 2}$; CoupTFIf $^{f / f}$ embryos. The neural tube is oriented toward the bottom of $A$, and toward the right side of $B-F$. Bar, $50 \mu \mathrm{m}$.

\section{Materials and methods}

Mice

The generation of Tie2-Cre, Rbpi ${ }^{+/ f}$, Prox $1^{+/ f}$, Coup-TFII $I^{+/ f}$, and PrOx $1^{+/ C r e E R T 2}$ mutant mice has been described previously (Kisanuki et al. 2001; Tanigaki et al. 2002; Harvey et al. 2005; Takamoto et al. 2005; Srinivasan et al. 2007). To generate the
Prox $1^{+/ G F P C r e}$ strain (Supplemental Fig. 1), we inserted a GFPCre fusion protein cassette downstream from the Prox1 translational start site. For positive selection, we inserted a neomycinresistant gene cassette downstream from GFPCre in the opposite orientation. For negative selection, we inserted a thymidine kinase gene outside the recombination arms.

To generate the Prox $1^{+/ N R m u t}$ mouse strain, we used PCR to generate a 2.5 -kb fragment upstream of the ATG of mouse Prox 1 and a $1.5-\mathrm{kb}$ fragment containing a fusion of synthetic avitagencoding sequence and Prox 1 exon 1 carrying the mutation in the sequence coding for the nuclear hormone-binding site, and then cloned the fragments into the PL452 plasmid. Avitag is a 17-amino-acid peptide (MSGLNDIFEAQKIEWHE) that can be biotinylated by the BirA biotin ligase, and therefore can be used for immunoprecipitation of tagged proteins using streptavidin (Schatz 1993; Scholle et al. 2004). This plasmid contained a neomycin selection cassette flanked by LoxP sites for positive selection and a cDNA cassette coding for diphtheria toxin chain A for negative selection.

Both targeting constructs were electroporated into W9.5 embryonic stem cells. Following selection and screening by Southern blot, the correctly targeted embryonic stem cells were used for the generation of chimeric mice. The neomycin cassette in the F1 Prox $1^{+/ N R m u t}$ mouse strain was removed by crossing it with a Vav-iCre transgenic line that is expressed in the germline (de Boer et al. 2003). All described mouse experiments were approved by the St. Jude Children's Research Hospital Animal Care and Use Committee.

\section{Antibodies}

The primary antibodies used were rabbit anti-Prox1 (AngioBio), goat anti-Proxl (R\&D Systems), rabbit anti- $\beta$-gal (MP Biomedicals), chicken anti- $\beta$-gal (Abcam), rat anti-PECAM (BD Pharmingen), rabbit anti-GFP (Molecular Probes), rabbit anti-CX40 (Alpha Diagnostic International), guinea pig anti-Lyve1 (our own), goat anti-Nrp2 (R\&D Systems), goat anti-Reelin (R\&D Systems), hamster anti-podoplanin (Hybridoma Bank), mouse anti-COUPTFII (Perseus Proteomics), rabbit anti-COUP-TFII (Tripodi et al. 2004), and mouse anti-PH3 (Upstate Biotechnologies). Secondary antibodies were Cy3-conjugated donkey anti-rabbit (Jackson ImmunoResearch Laboratories), Cy3-conjugated donkey antimouse (Jackson ImmunoResearch Laboratories), Cy3-conjugated goat anti-chicken (Rockland), Cy3-conjugated donkey anti-goat (Jackson ImmunoResearch Laboratories), Cy3-conjugated goat anti-hamster (Jackson ImmunoResearch Laboratories), Alexa 488conjugated donkey anti-rat (Molecular Probes), Alexa 488-conjugated donkey anti-goat (Molecular Probes), Alexa 488-conjugated goat antichicken (Molecular Probes), Alexa 488-conjugated goat anti-guinea pig (Molecular Probes), Alexa 488-conjugated donkey antigoat (Molecular Probes), Alexa 488-conjugated goat anti-hamster (Molecular Probes), Alexa 488-conjugated donkey anti-mouse (Molecular Probes), Cy5-conjugated donkey anti-guinea pig (Jackson ImmunoResearch Laboratories), and Cy5-conjugated donkey anti-rat (Jackson ImmunoResearch Laboratories). Mouse anti-COUP-TFII was used for immunostaining of E10.5 sections, and rabbit antiCOUP-TFII was used for staining sections at later embryonic stages. The sections were mounted using VectaShield mounting media containing DAPI (Vector Laboratories).

\section{Image analysis}

Tissue sections prepared on a cryostat were immunostained with antibodies specific for GFP and PECAM and then photographed with a confocal laser-scanning microscope (Zeiss) at identical LASER power and settings. Subsequently, the images were 

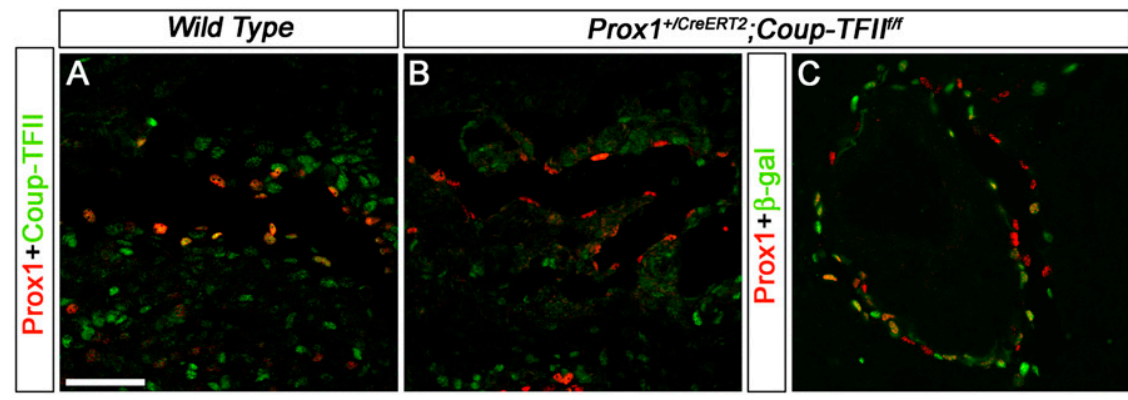

Figure 6. Prox1 expression is normal in the remaining Coup-TFII-null LECs of E15.5 Prox $^{+/ \text {CreERT2 }}$;Coup-TFIf ${ }^{f / f}$ embryos exposed to TM at E12.5. (A) At E15.5, dermal lymphatic vessels are lined by Prox $1^{+}$Coup-TFII ${ }^{+}$ LECs in wild-type embryos. $(B)$ The Prox $1^{+}$ LECs of Prox $1^{+/ C r e E R T 2}$;Coup-TFIf ${ }^{f / f}$ littermates are negative for Coup-TFII. (C) $\beta$-gal staining shows the efficient deletion of Coup-TFII in the remaining Prox1-expressing LECs. The neural tube is oriented toward the right side of all panels. Bar, $50 \mu \mathrm{m}$.

analyzed using NIS Elements AR 3.0 image analysis software (Nikon) to quantify the intensities of the fluorochromes.

\section{Bioinformatics}

We downloaded 5-kb upstream sequences, the $5^{\prime}$ untranslated region (UTR), and the first intron (up to start site ATG) of Prox1 genes from human, mouse, rat, and chimpanzee data on the University of California at Santa Cruz genome browser. We searched the V\$ARP1_1 matrix (for putative Coup-TFII-binding sites) derived from Transfac version 2009.1 (Matys et al. 2006) and mapped to the upstream sequences using matrix scan (ThomasChollier et al. 2008). Multiple sequence alignment was performed using Lasergene MegAlign software (DNASTAR, Inc.).

\section{EMSA}

EMSA was carried out as described previously (Jeong et al. 2008), with the exception of 293T cells being used instead of COS7 cells for the ectopic expression of COUP-TFII. For ectopic expression, the CMV6-XL5 expression plasmid containing the full-length COUP-TFII cDNA was purchased from Origene.

The probe was generated by amplifying the Coup-TFII-binding site identified in the mouse Prox 1 regulatory region using the specific forward and reverse primers EMSA1 and EMSA2 (Supplemental Table 1). Two additional primers, EMSA mut1 and EMSA mut2 (Supplemental Table 1), were used to generate the mutation in the Coup-TFII-binding site by PCR. Mouse monoclonal antibody against COUP-TFII was used for the supershift.

\section{ChIP}

Human LECs (Lonza) were maintained in culture per the manufacturers' suggestions. ChIP was performed as described previously (Geng et al. 2008). The sheared chromatin was precleared using rabbit anti-IgG antibody (Santa Cruz Biotechnologies). Subsequently, ChIP was carried out with or without the rabbit anti-COUP-TFII antibody. Following the pull-down of the chromatin fragments, real-time PCR was carried out using primers and probes specific for the conserved COUP-TFII-binding

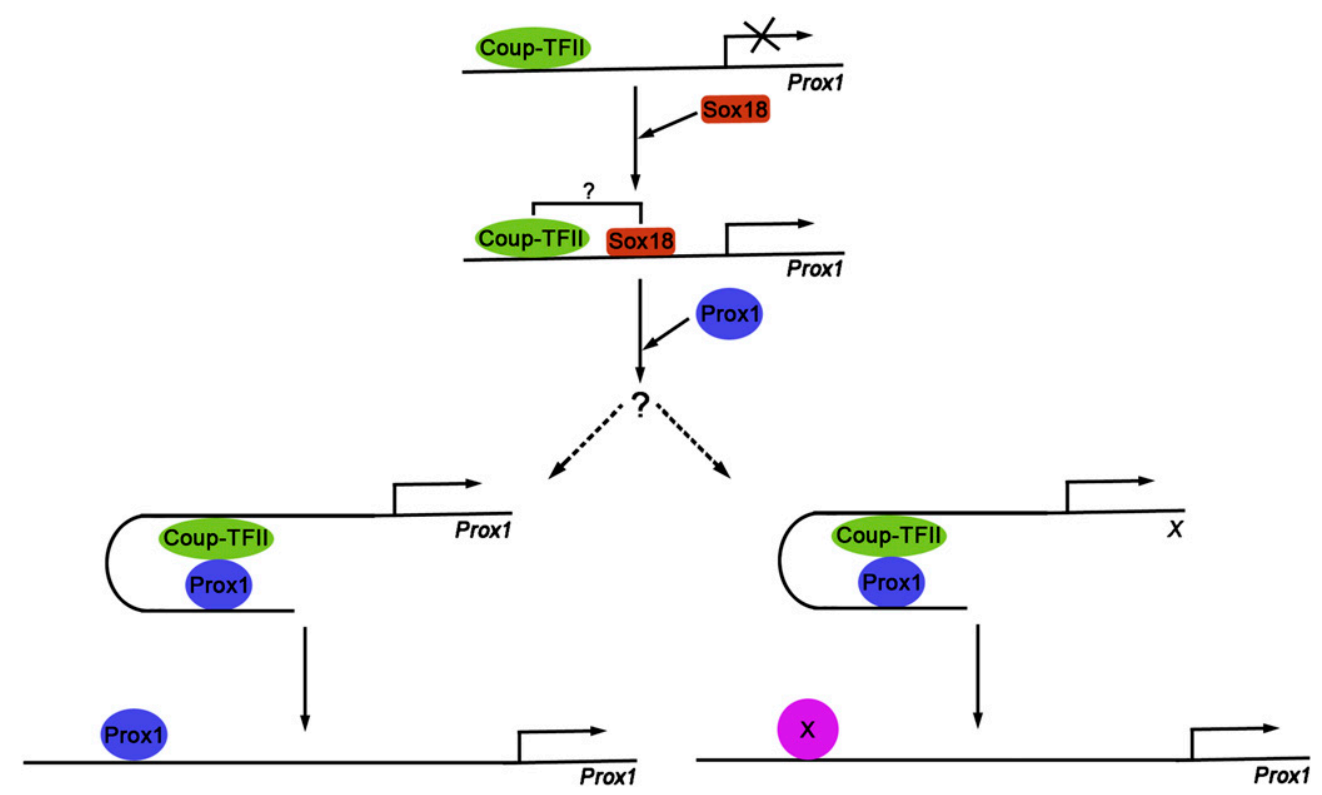

Figure 7. Model of the roles of Coup-TFII in the regulation of Prox1 expression during lymphatic vascular development. Coup-TFII alone is not sufficient to induce Prox1 expression in LECs. Therefore, in this working model, we suggest that Coup-TFII cooperates with Sox18 to initiate Prox1 expression in LEC progenitors. Once initiated, two mechanisms may maintain Prox1 expression in differentiating LECs. Proxl could be recruited to its own promoter due to its interaction with Coup-TFII and subsequently regulate and maintain its own expression. Alternatively, the Coup-TFII-Prox1 complex might activate an as-yet-unknown transcription factor X, which in turn maintains Prox1 expression. 
site (ChIP1-3), the nonconserved COUP-TFII-binding site (ChIP46), and the nonspecific control site (ChIP7-9) (Supplemental Table 1). Real-time PCR was carried out according to the manufacturers' instructions (Applied Biosystems).

\section{Luciferase reporter gene assays}

Synthetic oligonucleotides containing six consecutive conserved Coup-TFII-binding sites were cloned into the pGL3 basic reporter construct (Promega). Two additional versions of this plasmid were made containing either 4- or 8-nt substitutions in each of the 16-nt repeats. All of the nucleotide sequences are provided in Supplemental Table 1. The generated reporter plasmids (100 ng), Renilla luciferase reporter under TK promoter (1 ng; Promega), and the indicated amount of COUP-TFII expression plasmid CMV6-XL5 (Origene) were mixed together and incubated with Fugene 6 transfection reagent (Roche) according to the manufacturers' instructions. Twenty-four hours prior to transfection, the $293 \mathrm{~T}$ cells were plated at a concentration of $50 \times 10^{3}$ cells per well into 24 -well plates. The DNAFugene 6 mix was split equally and added to four wells of the 24-well plates. Thirty-six hours later, the cells were harvested, and the Dual luciferase assay (Promega) was performed according to the manufacturers' instructions. The ratio of firefly to renilla luciferase activities (RLU) was measured, and the average and standard deviation were documented as the fold induction.

\section{TM administration}

TM preparation and intraperitoneal injections of pregnant dams were carried out as described previously (Srinivasan et al. 2007). Gavage of pups with TM was also done as described previously (Johnson et al. 2008).

\section{In situ hybridization, immunohistochemistry, Western} blotting, detection of LacZ activity, and TUNEL assay

Whole-mount X-gal staining and immunostaining were carried out as described previously (Harvey et al. 2005; Srinivasan et al. 2007). Fluorescent immunohistochemistry and in situ hybridization were performed as described previously (Srinivasan et al. 2007). Western blots were carried out using standard protocols and a monoclonal antibody against COUP-TFII. TUNEL assay was performed as described previously (Geng et al. 2008).

\section{Viral constructs and viral particle generation}

Full-length Prox1 or avitag-Prox1 cDNAs were cloned into a two-promoter MSCV-fl-sv-Puro retroviral vector containing the LTR promoter and an SV40-Puro selection cassette. Viral particles pseudotyped with VSV-G and PEQ-PAM were generated by transient transfection in $293 \mathrm{~T}$ cells. Briefly, $293 \mathrm{~T}$ cells were plated at $2 \times 10^{6}$ cells per 100 -mm-diameter tissue culture dish and transfected with the retroviral vector (empty or containing Prox1 or avitag-Prox1) using standard protocols. At $12 \mathrm{~h}$ posttransfection, the medium was replaced with fresh DMEM containing $10 \%$ FBS, and cells were grown for an additional $24 \mathrm{~h}$. The conditioned medium containing recombinant retroviruses was collected and was filtered through polysulfonic filters (pore size, $0.45 \mathrm{~mm}$; Corning).

\section{Viral infection and generation of stable cell lines}

For retroviral infections, H5V cells were plated at a density of $10^{6}$ cells per 100-mm-diameter tissue culture dish. Eighteen hours later, retrovirus supernatants and $8 \mathrm{mg} / \mathrm{mL}$ Polybrene (Sigma) were applied to the H5V cells and incubated for $12 \mathrm{~h}$. Selection with $1.5 \mathrm{mg} / \mathrm{mL}$ puromycin was initiated $12 \mathrm{~h}$ after infection. After selection for $\sim 10 \mathrm{~d}$, cells were seeded at $1 \times 10^{4}$ cells per 100-mm-diameter tissue culture dish. Individual clones were picked, transferred to 24-well plates, and expanded to generate cells that stably expressed WT-Prox1 or avitag-Prox1.

\section{Immunofluorescence microscopy}

Transduced H5V cells and human LECs were fixed on ice in $2 \%$ paraformaldehyde for 10 min and subsequently in $100 \%$ methanol for $1 \mathrm{~min}$. Cells were washed three times for $5 \mathrm{~min}$ each in PBS at room temperature, permeabilized, and blocked in $0.01 \%$ Triton X-100, 2\% FBS, and 0.5\% BSA in PBS for $30 \mathrm{~min}$ at room temperature. They were then incubated with the indicated primary antibodies and subsequently with the corresponding secondary antibodies. Slides were mounted in VectaShield mounting medium (Vector Laboratories) and photographed.

\section{Acknowledgments}

We thank Drs. S. Tsai and M.-J. Tsai for providing the CoupTFII floxed mouse strain; Dr. J. Westmoreland for the Prox $1^{+/ f l o x} ; R 26 R$ mouse strain; Dr. J. Johnson for the Rbpi floxed mouse strain; Dr. Y. Lee for help with the design of primers and probes for real-time PCR; Drs. J. Downing, S. Baker, and R. Endersby for providing the GFPCre cDNA cassette; Drs. F. Mathias and P. Koopmann for the Sox18 in situ probe; Dr. M. Yanagisawa for the Tie2-Cre strain; Dr. E. Dejana for the H5V cells; Mr. S. Connell, Dr. L. Zhao, Dr. Y. Ouyang and Dr. J. Peterson for help with confocal imaging; and Dr. A. McArthur for editing of this manuscript. We thank all of the members of our laboratory for their helpful suggestions and discussions. This work was supported by NIH grant R01-HL073402 (to G.O) and the American Lebanese Syrian Associated Charities (ALSAC).

\section{References}

Bull LN, Roche E, Song EJ, Pedersen J, Knisely AS, van Der Hagen CB, Eiklid K, Aagenaes O, Freimer NB. 2000. Mapping of the locus for cholestasis-lymphedema syndrome (Aagenaes syndrome) to a 6.6-cM interval on chromosome 15q. Am J Hum Genet 67: 994-999.

de Boer J, Williams A, Skavdis G, Harker N, Coles M, Tolaini M, Norton T, Williams K, Roderick K, Potocnik AJ, et al. 2003. Transgenic mice with hematopoietic and lymphoid specific expression of Cre. Eur I Immunol 33: 314-325.

Delorme B, Dahl E, Jarry-Guichard T, Briand JP, Willecke K, Gros D, Theveniau-Ruissy M. 1997. Expression pattern of connexin gene products at the early developmental stages of the mouse cardiovascular system. Circ Res 81: 423-437.

Francois M, Caprini A, Hosking B, Orsenigo F, Wilhelm D, Browne C, Paavonen K, Karnezis T, Shayan R, Downes M, et al. 2008. Sox18 induces development of the lymphatic vasculature in mice. Nature 456: 643-647.

Fruhwirth M, Janecke AR, Muller T, Carlton VE, Kronenberg F, Offner F, Knisely AS, Geleff S, Song EJ, Simma B, et al. 2003. Evidence for genetic heterogeneity in lymphedema-cholestasis syndrome. J Pediatr 142: 441-447.

Geng X, Speirs C, Lagutin O, Inbal A, Liu W, Solnica-Krezel L, Jeong Y, Epstein DJ, Oliver G. 2008. Haploinsufficiency of Six3 fails to activate Sonic hedgehog expression in the ventral forebrain and causes holoprosencephaly. Dev Cell 15: $236-247$.

Harvey NL, Srinivasan RS, Dillard ME, Johnson NC, Witte MH, Boyd K, Sleeman MW, Oliver G. 2005. Lymphatic vascular 
defects promoted by Prox 1 haploinsufficiency cause adultonset obesity. Nat Genet 37: 1072-1081.

Jeong Y, Leskow FC, El-Jaick K, Roessler E, Muenke M, Yocum A, Dubourg C, Li X, Geng X, Oliver G, et al. 2008. Regulation of a remote Shh forebrain enhancer by the Six3 homeoprotein. Nat Genet 40: 1348-1353.

Johnson NC, Dillard ME, Baluk P, McDonald DM, Harvey NL, Frase SL, Oliver G. 2008. Lymphatic endothelial cell identity is reversible and its maintenance requires Proxl activity. Genes \& Dev 22: 3282-3291.

Kato H, Taniguchi Y, Kurooka H, Minoguchi S, Sakai T, Nomura-Okazaki S, Tamura K, Honjo T. 1997. Involvement of RBP-J in biological functions of mouse Notch1 and its derivatives. Development 124: 4133-4141.

Kisanuki YY, Hammer RE, Miyazaki J, Williams SC, Richardson JA, Yanagisawa M. 2001. Tie2-Cre transgenic mice: A new model for endothelial cell-lineage analysis in vivo. Dev Biol 230: 230-242.

Krebs LT, Shutter JR, Tanigaki K, Honjo T, Stark KL, Gridley T. 2004. Haploinsufficient lethality and formation of arteriovenous malformations in Notch pathway mutants. Genes \& Dev 18: 2469-2473.

Lee S, Kang J, Yoo J, Ganesan SK, Cook SC, Aguilar B, Ramu S, Lee I, Hong YK. 2009. Prox1 physically and functionally interacts with COUP-TFII to specify lymphatic endothelial cell fate. Blood 113: 1856-1859.

Li L, Xie X, Qin J, Jeha GS, Saha PK, Yan J, Haueter CM, Chan L, Tsai SY, Tsai MJ. 2009. The nuclear orphan receptor COUPTFII plays an essential role in adipogenesis, glucose homeostasis, and energy metabolism. Cell Metab 9: 77-87.

Liu YW, Gao W, Teh HL, Tan JH, Chan WK. 2003. Proxl is a novel coregulator of Fflb and is involved in the embryonic development of the zebra fish interrenal primordium. Mol Cell Biol 23: 7243-7255.

Matys V, Kel-Margoulis OV, Fricke E, Liebich I, Land S, BarreDirrie A, Reuter I, Chekmenev D, Krull M, Hornischer K, et al. 2006. TRANSFAC and its module TRANSCompel: Transcriptional gene regulation in eukaryotes. Nucleic Acids Res 34: D108-D110. doi: 10.1093/nar/gkj143.

Oliver G, Alitalo K. 2005. The lymphatic vasculature: Recent progress and paradigms. Annu Rev Cell Dev Biol 21: 457483.

Oliver G, Srinivasan RS. 2008. Lymphatic vasculature development: Current concepts. Ann N Y Acad Sci 1131: 75-81.

Pennisi D, Gardner J, Chambers D, Hosking B, Peters J, Muscat G, Abbott C, Koopman P. 2000. Mutations in Sox 18 underlie cardiovascular and hair follicle defects in ragged mice. Nat Genet 24: 434-437.

Qin J, Gao DM, Jiang QF, Zhou Q, Kong YY, Wang Y, Xie YH. 2004. Prospero-related homeobox (Proxl) is a corepressor of human liver receptor homolog-1 and suppresses the transcription of the cholesterol 7- $\alpha$-hydroxylase gene. Mol Endocrinol 18: 2424-2439.

Schatz PJ. 1993. Use of peptide libraries to map the substrate specificity of a peptide-modifying enzyme: A 13 residue consensus peptide specifies biotinylation in Escherichia coli. Biotechnology 11: 1138-1143.

Scholle MD, Collart FR, Kay BK. 2004. In vivo biotinylated proteins as targets for phage-display selection experiments. Protein Expr Purif 37: 243-252.

Soriano P. 1999. Generalized lacZ expression with the ROSA26 Cre reporter strain. Nat Genet 21: 70-71.

Srinivasan RS, Dillard ME, Lagutin OV, Lin FJ, Tsai S, Tsai MJ, Samokhvalov IM, Oliver G. 2007. Lineage tracing demonstrates the venous origin of the mammalian lymphatic vasculature. Genes \& Dev 21: 2422-2432.
Steffensen KR, Holter E, Bavner A, Nilsson M, Pelto-Huikko M, Tomarev S, Treuter E. 2004. Functional conservation of interactions between a homeodomain cofactor and a mammalian FTZ-F1 homologue. EMBO Rep 5: 613-619.

Takamoto N, You LR, Moses K, Chiang C, Zimmer WE, Schwartz RJ, DeMayo FJ, Tsai MJ, Tsai SY. 2005. COUP-TFII is essential for radial and anteroposterior patterning of the stomach. Development 132: 2179-2189.

Tanigaki K, Han H, Yamamoto N, Tashiro K, Ikegawa $M$, Kuroda K, Suzuki A, Nakano T, Honjo T. 2002. NotchRBP-J signaling is involved in cell fate determination of marginal zone B cells. Nat Immunol 3: 443-450.

Thomas-Chollier M, Sand O, Turatsinze JV, Janky R, Defrance M, Vervisch E, Brohee S, van Helden J. 2008. RSAT: Regulatory sequence analysis tools. Nucleic Acids Res 36: W119W127. doi: 10.1093/nar/gkn304.

Tripodi M, Filosa A, Armentano M, Studer M. 2004. The COUPTF nuclear receptors regulate cell migration in the mammalian basal forebrain. Development 131: 6119-6129.

Wang L, Zhu J, Shan S, Qin Y, Kong Y, Liu J, Wang Y, Xie Y. 2008. Repression of interferon- $\gamma$ expression in $T$ cells by Prospero-related homeobox protein. Cell Res 18: 911-920.

Wigle JT, Oliver G. 1999. Proxl function is required for the development of the murine lymphatic system. Cell 98: 769778.

Wigle JT, Harvey N, Detmar M, Lagutina I, Grosveld G, Gunn MD, Jackson DG, Oliver G. 2002. An essential role for Prox1 in the induction of the lymphatic endothelial cell phenotype. EMBO J 21: 1505-1513.

Yamazaki T, Yoshimatsu Y, Morishita Y, Miyazono K, Watabe T. 2009. COUP-TFII regulates the functions of Proxl in lymphatic endothelial cells through direct interaction. Genes Cells 14: 425-434.

You LR, Lin FJ, Lee CT, DeMayo FJ, Tsai MJ, Tsai SY. 2005. Suppression of Notch signalling by the COUP-TFII transcription factor regulates vein identity. Nature 435: 98-104. 


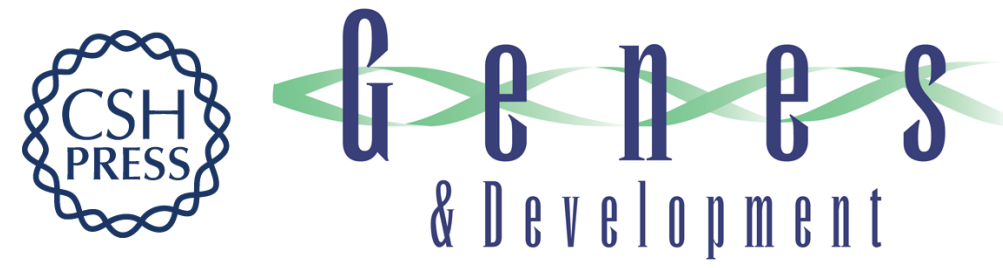

\section{The nuclear hormone receptor Coup-TFII is required for the initiation and early maintenance of Prox1 expression in lymphatic endothelial cells}

R. Sathish Srinivasan, Xin Geng, Ying Yang, et al.

Genes Dev. 2010, 24:

Access the most recent version at doi:10.1101/gad.1859310

Supplemental http://genesdev.cshlp.org/content/suppl/2010/03/31/24.7.696.DC1

Material

References This article cites 34 articles, 11 of which can be accessed free at: http://genesdev.cshlp.org/content/24/7/696.full.html\#ref-list-1

License

Email Alerting Receive free email alerts when new articles cite this article - sign up in the box at the top Service right corner of the article or click here.

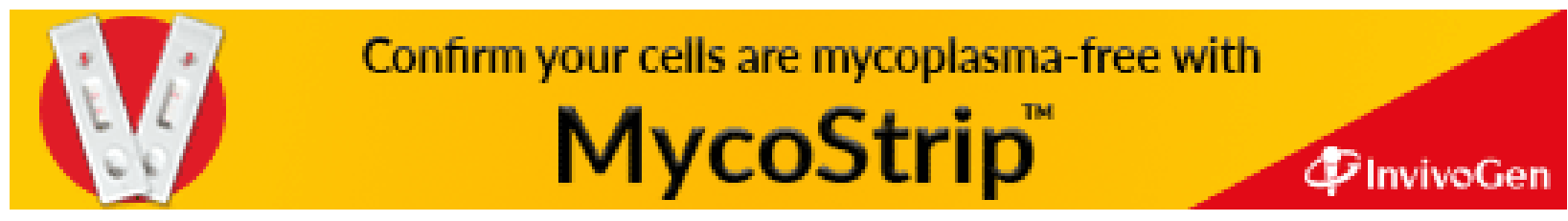

